\title{
Direct synthesis of one-dimensional silicon carbide nanostructures on graphite by pyrolysis of rice husks
}

\author{
Jin LI, Takashi SHIRAI ${ }^{\dagger}$ and Masayoshi FUJI \\ Advanced Ceramics Research Center, Nagoya Institute of Technology, 3-101-1 Hommachi, Tajimi, Gifu 507-0033, Japan
}

\begin{abstract}
One-dimensional (1D) $\beta$-SiC/SiO ${ }_{2}$ nanochains, $\beta$-SiC nanowires and rod-like $\beta$-SiC were directly obtained from the vapor deposited products that formed on graphite by pyrolysis of rice husks (RHs) in argon atmosphere. 1D $\beta$-SiC/SiO $\mathrm{Sanochains}_{2}$ composed of $\beta$-SiC stems and amorphous $\mathrm{SiO}_{2}$ beads were synthesized at $1500^{\circ} \mathrm{C}$ for $2 \mathrm{~h}$. Pure $1 \mathrm{D} \beta$-SiC nanowires having diameter of around $160 \mathrm{~nm}$ and tens of micrometers in length were obtained at $1500^{\circ} \mathrm{C}$ for 4 and $6 \mathrm{~h}$. As pyrolysis temperature was increased to 1600 and $1700^{\circ} \mathrm{C}, \beta$-SiC nanowires and rod-like $\beta$-SiC with larger diameters and shorter lengths were received, respectively. The possible growth processes based on vapor-solid (VS) mechanism were proposed to explain the formation of the 1D $\beta$-SiC nanostructures.
\end{abstract}

(C)2013 The Ceramic Society of Japan. All rights reserved.

Key-words : Rice husks, $\beta$-SiC, Nanowires, Nanochains, Microstructure

[Received November 5, 2012; Accepted November 21, 2012]

\section{Introduction}

Recently, one-dimensional (1D) silicon carbide (SiC) nanostructures have drawn a great attention due to their versatile physical and chemical properties such as high thermal stability and hardness, chemical inertness, wide band gap and unique optical performance. ${ }^{1)-3)}$ These unique properties make 1D SiC nanostructures suitable for various applications such as nanocomposites ${ }^{4)}$ microelectronics,${ }^{5)}$ optoelectronics, ${ }^{6)}$ catalyst supports, ${ }^{7)}$ etc. A variety of techniques for fabricating $1 \mathrm{D} \mathrm{SiC}$ nanostructures, particularly $\mathrm{SiC}$ nanowires, have been developed, including chemical vapor deposition (CVD), ${ }^{8), 9)}$ carbon nanotube confined reaction, ${ }^{10)}$ arc-discharge, ${ }^{11)}$ metal catalyst-assisted vapor-liquid-solid (VLS) growth ${ }^{12), 13)}$ and carbothermal reduction. ${ }^{14)}$ However, most of these methods involved complex procedures, expensive precursors or usage of metal catalyst. Therefore, more simple and low-cost approaches are still needed for synthesis of 1D SiC nanostructures.

Rice husks (RHs), a prolific and low-cost agricultural byproduct, is considered as a good candidate for fabricating $\mathrm{SiC}$ due to the high contents of $\mathrm{SiO}_{2}$ and $\mathrm{C}$. According to the formation mechanism of $\mathrm{SiC}$ by pyrolysis of $\mathrm{RHs},{ }^{15)-17)}$ it can be known that the producing of $\mathrm{SiO}$ and $\mathrm{CO}$ vapors is inevitable by reactions (1)-(3):

$$
\begin{aligned}
& \mathrm{SiO}_{2}(\mathrm{~s})+\mathrm{C}(\mathrm{s}) \rightarrow \mathrm{SiO}(\mathrm{g})+\mathrm{CO}(\mathrm{g}) \\
& \mathrm{SiO}_{2}(\mathrm{~s})+\mathrm{CO}(\mathrm{g}) \rightarrow \mathrm{SiO}(\mathrm{g})+\mathrm{CO}_{2}(\mathrm{~g}) \\
& \mathrm{C}(\mathrm{s})+\mathrm{CO}_{2}(\mathrm{~g}) \rightarrow 2 \mathrm{CO}(\mathrm{g})
\end{aligned}
$$

Thus, large amounts of these vapors will diffuse to the inner surface of crucible walls and form the vapor deposited products of $\mathrm{SiC}$ by via reaction (4) and (5):

$$
\begin{aligned}
& \mathrm{SiO}(\mathrm{g})+2 \mathrm{C}(\mathrm{s}) \rightarrow \mathrm{SiC}(\mathrm{s})+\mathrm{CO}(\mathrm{g}) \\
& \mathrm{SiO}(\mathrm{g})+3 \mathrm{CO}(\mathrm{g}) \rightarrow \mathrm{SiC}(\mathrm{s})+2 \mathrm{CO}_{2}(\mathrm{~g})
\end{aligned}
$$

In this study, several kinds of $1 \mathrm{D} \mathrm{SiC}$ nanostructures were synthesized from the vapor deposited products by pyrolysis of RHs in argon atmosphere. The effects of pyrolysis temperature

\footnotetext{
Corresponding author: T. Shirai; E-mail: shirai@nitech.ac.jp
}

and time on morphology and microstructure of $1 \mathrm{D} \mathrm{SiC} \mathrm{nano-}$ structures were investigated in details.

\section{Experimental section}

RHs were obtained from a local rice mill factory of Japan. The RHs are composed of about 75 mass $\%$ organic constituents (hemicelluloses, cellulose and lignin), 5 mass $\%$ water, 18 mass $\%$ $\mathrm{SiO}_{2}$ and 2 mass $\%$ other impurities $\left(0.88\right.$ mass $\% \mathrm{~K}_{2} \mathrm{O}, 0.46$ mass $\% \mathrm{SO}_{3}, 0.31$ mass $\% \mathrm{Al}_{2} \mathrm{O}_{3}, 0.23$ mass $\% \mathrm{CaO}, 0.07$ mass $\%$ $\mathrm{P}_{2} \mathrm{O}_{5}, 0.04$ mass $\% \mathrm{MnO}$ and 0.01 mass $\left.\% \mathrm{Fe}_{2} \mathrm{O}_{3}\right)$. In a typical procedure, $6 \mathrm{~g}$ RHs were placed in a cubic graphite crucible $(80 \times 80 \times 10 \mathrm{~mm})$ and covered by a graphite plate. The graphite crucible was put into a vertical graphite furnace. After evacuating to $\sim 5 \mathrm{~Pa}$ by a rotary pump, high-purity argon gas (>99.999\%) was introduced to the furnace at a flow rate of $2 \mathrm{~L} / \mathrm{min}$ and maintained at a positive pressure of $\sim 50 \mathrm{kPa}$ throughout the whole following experiment. The furnace was firstly heated to $1000^{\circ} \mathrm{C}$ at a rate of $15^{\circ} \mathrm{C} / \mathrm{min}$ and then up to target temperature at a rate of $10^{\circ} \mathrm{C} / \mathrm{min}$. Pyrolysis of RHs were carried out at $1500^{\circ} \mathrm{C}$ for $2,4,6 \mathrm{~h}$ and at $1600,1700^{\circ} \mathrm{C}$ for $2 \mathrm{~h}$, respectively. After the pyrolysis process, the furnace was cooled to room temperature naturally. Finally, the film-like vapor deposited products formed on graphite were collected.

The as-received products were characterized by X-ray diffraction using an X-ray diffractometer (XRD, Rigaku, UltimaIV) with $\mathrm{Cu} K \alpha(\lambda=1.5406 \AA)$ radiation, Fourier transform infrared spectra recorded on a FT-IR spectrophotometer (FT-IR, JASCO, FT/IR 6200), field emission scanning electron microscopy (FESEM, JEOL, JSM-7600F), transmission electron microscopy (TEM, JEOL, JEM2010) and selected area electron diffraction (SAED).

\section{Results and discussion}

Figure 1 shows the XRD patterns of the as-received products and reveals the formation of $\beta$-SiC. The diffraction peaks at $2 \theta=35.6,41.4,60.0,71.8,75.5^{\circ}$ can be indexed as (111), (200), (220), (311) and (222) reflections of $\beta$-SiC structure (JCPDS Card No. 29-1129). The stronger (111) diffraction peak indicates that [111] is the dominant growth direction of the $\beta$-SiC. The 


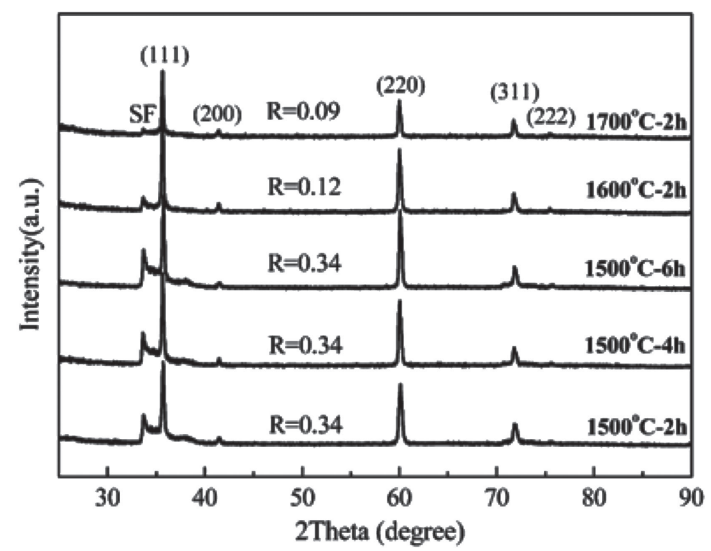

Fig. 1. XRD patterns of the as-received products.

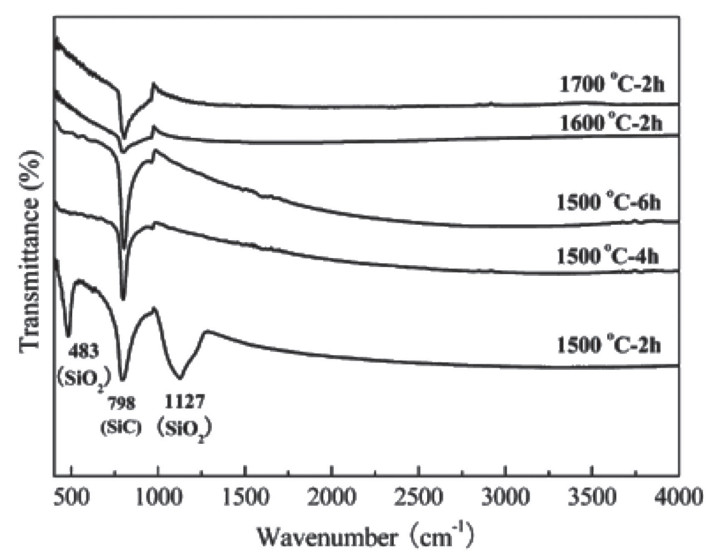

Fig. 2. FT-IR spectra of the as-received products.

small peak at $33.6^{\circ}$ marked with $\mathrm{SF}$ is attributed to the stacking faults of $\beta$-SiC. ${ }^{18)}$ The intensity ratio of the peaks at 33.6 and $41.4^{\circ}\left(\mathrm{R}=\mathrm{I}_{33.6^{\circ}} / \mathrm{I}_{41.4^{\circ}}\right)$ can be used as indicator of stacking faults density. ${ }^{19)}$ In our case, the products obtained at $1500^{\circ} \mathrm{C}$ for different duration have a same $\mathrm{R}$ value of 0.34 . As the pyrolysis temperature increase to 1600 and $1700^{\circ} \mathrm{C}$, the $\mathrm{R}$ value decrease to 0.12 and 0.09 , respectively. It seems that lower density of stacking faults is formed at higher temperature, whereas the products obtained at $1500^{\circ} \mathrm{C}$ for different duration have a same density of stacking faults.

Figure 2 displays the FT-IR spectra of the as-received products. The absorption peak at around $798 \mathrm{~cm}^{-1}$ corresponds to $\mathrm{Si}-\mathrm{C}$ stretching vibration of $\beta$-SiC. Whereas the characteristic peaks at 1127 and $483 \mathrm{~cm}^{-1}$ are ascribed to the $\mathrm{Si}-\mathrm{O}$ stretching vibration of amorphous $\mathrm{SiO}_{2}{ }^{20)}$ Thus, it can be concluded that a composite of $\beta$-SiC and amorphous $\mathrm{SiO}_{2}$ is received at $1500^{\circ} \mathrm{C}$ for $2 \mathrm{~h}$, while other products are pure $\beta$-SiC.

As shown in Figs. 3(a) and 3(b), the product obtained at $1500^{\circ} \mathrm{C}$ for $2 \mathrm{~h}$ mainly consists of nanochains structure having one stem with diameters of $150-160 \mathrm{~nm}$ and tens of micrometers in length. The beads periodically disperse on the stem with a nearly equal distance of around $600 \mathrm{~nm}$. Figure 4(a) presents the TEM image of a typical single $\beta-\mathrm{SiC} / \mathrm{SiO}_{2}$ nanochain. It can be known that the stem is crystalline $\beta$-SiC, whereas the beads are amorphous $\mathrm{SiO}_{2}$. As shown in the high magnification TEM image of a $\beta$ - $\mathrm{SiC} / \mathrm{SiO}_{2}$ heterojunction structure [inset of Fig. 4(a)], there are lots of stacking faults on the $\beta$-SiC stems and the amorphous $\mathrm{SiO}_{2}$ beads prefer to form on the surface where
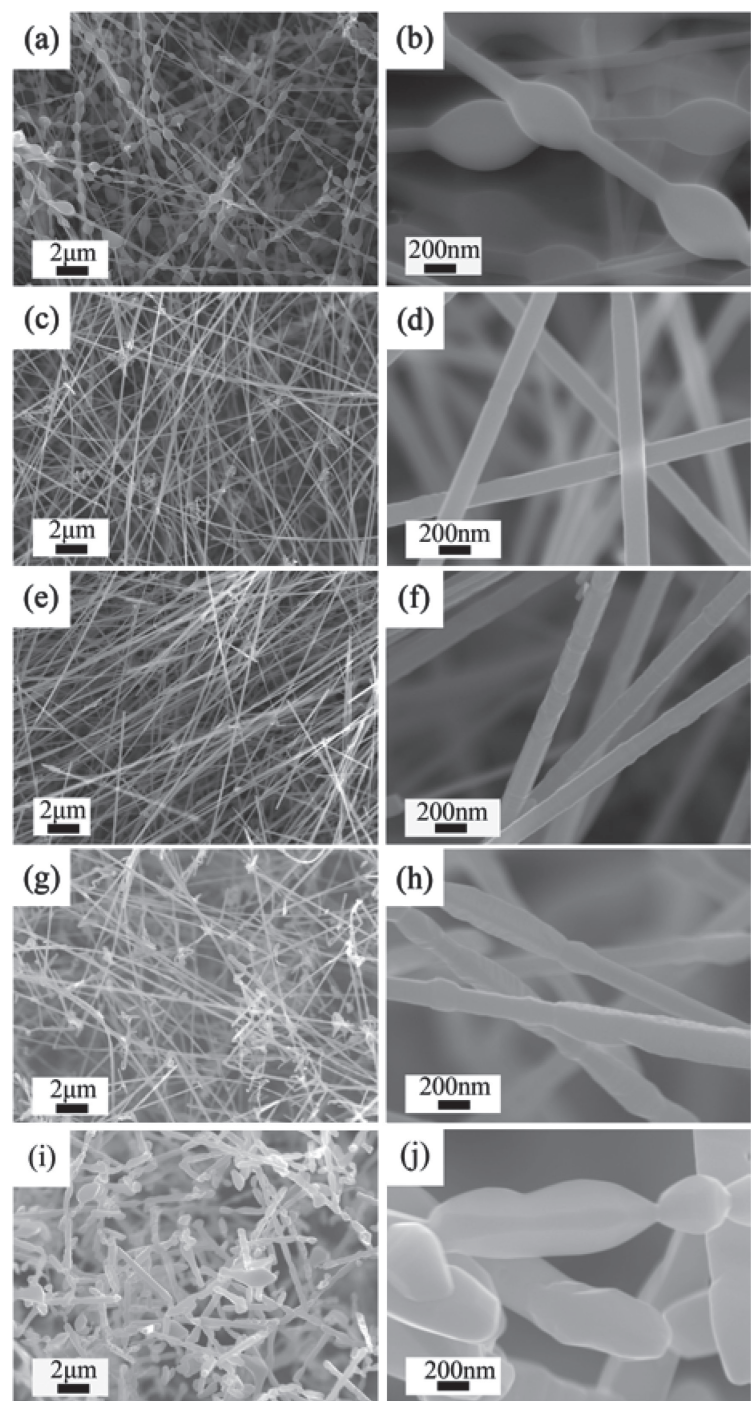

Fig. 3. FESEM images of the as-received products obtained at: $(\mathrm{a}, \mathrm{b})$ $1500^{\circ} \mathrm{C}$ for $2 \mathrm{~h}$; (c, d) $1500^{\circ} \mathrm{C}$ for $4 \mathrm{~h}$; (e, f) $1500^{\circ} \mathrm{C}$ for $6 \mathrm{~h} ;(\mathrm{g}, \mathrm{h}) 1600^{\circ} \mathrm{C}$ for $2 \mathrm{~h}$; (i, j) $1700^{\circ} \mathrm{C}$ for $2 \mathrm{~h}$.

more stacking faults exist. Bright spots as well as obvious streaks can be observed in the selected area electron diffraction (SAED) pattern of the $\beta-\mathrm{SiC} / \mathrm{SiO}_{2}$ heterojunction structure [Fig. 4(b)], indicating that the $\beta$-SiC stem grows along [111] in length direction and having lots of stacking faults.

Figures 3(c)-3(j) show the FESEM images of the products obtained at $1500^{\circ} \mathrm{C}$ for $4,6 \mathrm{~h}$ and at $1600,1700^{\circ} \mathrm{C}$ for $2 \mathrm{~h}$, respectively. The products obtained at $1500^{\circ} \mathrm{C}$ for 4 and $6 \mathrm{~h}$ are $\beta$-SiC nanowires having tens of micrometers in length and uniform diameter of around $160 \mathrm{~nm}$. As the pyrolysis temperature increase to $1600^{\circ} \mathrm{C}$, however, the as-received $\beta$-SiC nanowires show shorter length and larger diameter. Moreover, the $\beta$-SiC obtained at $1700^{\circ} \mathrm{C}$ for $2 \mathrm{~h}$ exhibits rod-like shapes with enhanced lateral growth.

Raman scattering is a useful method for the characterization of nanostructured materials and a qualitative probe of lattice defects. According to previous research, bulk $\beta$-SiC has two strong characteristic peaks at 796 and $980 \mathrm{~cm}^{-1}$, which correspond to the transverse optical (TO) phonon mode and longitudinal optical (LO) phonon mode at the $\Gamma$ point of $\beta$-SiC, respectively. ${ }^{21)}$ As shown in the Raman spectra of the as-received products (Fig. 5), 


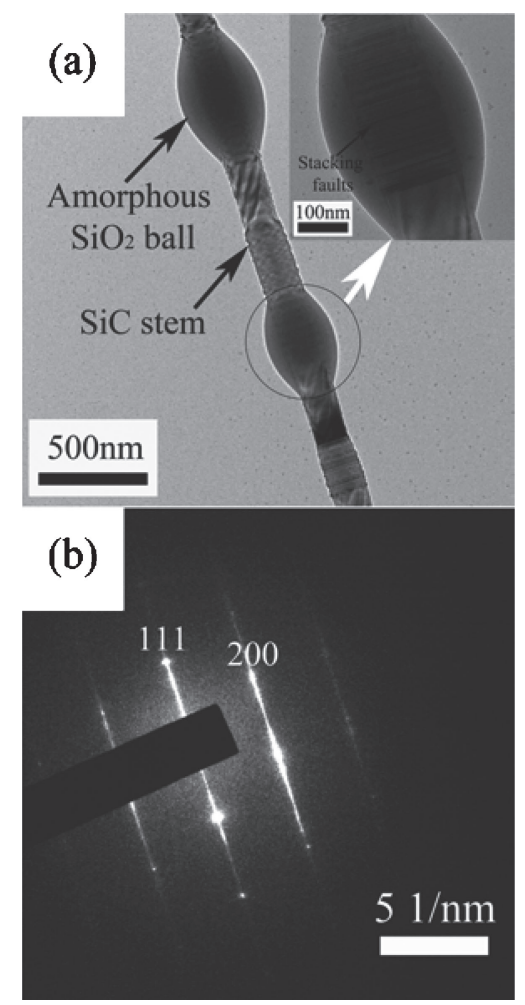

Fig. 4. (a) TEM image of a typical single $\beta-\mathrm{SiC} / \mathrm{SiO}_{2}$ nanochain. The inset is the high magnification TEM image of a typical $\beta-\mathrm{SiC} / \mathrm{SiO}_{2}$ heterojunction structure. (b) SAED pattern of the $\beta-\mathrm{SiC} / \mathrm{SiO}_{2}$ heterojunction structure.

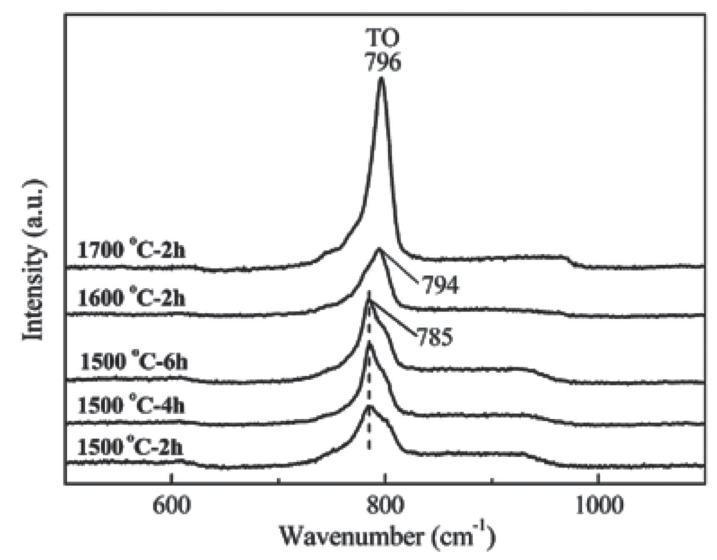

Fig. 5. Raman spectra of the as-received products.

however, no obvious LO phonon peak can be observed, which is similar to the results reported by Fréchette et al. ${ }^{22)}$ and $\mathrm{Li}$ et al. ${ }^{23)}$ The products obtained at $1500^{\circ} \mathrm{C}$ for different time have an intensive TO phonon peak with a same peak position at $785 \mathrm{~cm}^{-1}$. Compared with bulk $\beta$-SiC, the obvious asymmetric broadening and down-shift are observed on the TO phonon peak, which can be ascribed to the size confinement effect and stacking faults of $\beta$-SiC nanostructures. ${ }^{24)}$ As the pyrolysis temperature up to 1600 and $1700^{\circ} \mathrm{C}$, the TO phonon peak shifts to 794 and $796 \mathrm{~cm}^{-1}$, respectively. Furthermore, weakened asymmetric broadening are observed, which is attributed to the larger diameter and lower density of stacking faults.

Because the 1D $\beta$-SiC nanostructures are synthesized without the aid of metal catalyst, vapor-solid (VS) growth mechanism is more plausible in this case. On the basis of the above experimental results, the possible growth mechanism of the 1D $\beta$-SiC nanostructures are suggested as follows:

The $\mathrm{SiO}$ and $\mathrm{CO}$ vapors generated via reactions (1)-(3) diffuse to the inner surface of graphite crucible. The $\mathrm{SiC}$ nucleuses are formed on graphite via reaction (4) and (5), and then grow up with continuous deposition to the $\beta$-SiC nanowires by reaction (5). Furthermore, the $\beta$-SiC nanowires prefer to grow along [111] direction due to the lowest surface energy. ${ }^{25)}$ However, reaction (5) can only occur under a supersaturated condition of $\mathrm{CO}$ at higher temperature. When pyrolysis was carried out at $1500^{\circ} \mathrm{C}$ for $2 \mathrm{~h}$, the reaction (5) cannot be finished completely. During the cooling stage, $\mathrm{SiO}$ vapor is prevail and reaction (6) will occur with generating $\mathrm{SiC}$ and $\mathrm{SiO}_{2}$ simultaneously.

$$
3 \mathrm{SiO}(\mathrm{g})+\mathrm{CO}(\mathrm{g}) \rightarrow \mathrm{SiC}(\mathrm{s})+2 \mathrm{SiO}_{2}(\mathrm{~s})
$$

Furthermore, part of the $\mathrm{SiO}_{2}$ is likely to react with the volatile of alkaline compound, which derives from the $\mathrm{K}_{2} \mathrm{O}$ in RHs, with forming poly alkaline silicates. Because the temperature in furnace is still higher than the melting point of poly alkaline silicates, the poly alkaline silicates show liquid phase and prefer to aggregate on the high stacking faults surfaces of $\beta$-SiC stem due to their better wettability and lower growth energy. ${ }^{26)}$ After continuous deposition of $\mathrm{SiO}_{2}$, the $\mathrm{SiO}_{2}$ beads are formed. When pyrolysis time is prolonged to 4 and $6 \mathrm{~h}$, the nanowires grow up entirely by reaction (5), resulting in pure $\beta$-SiC nanowires. On the other hand, the reaction rate becomes higher and the lateral growth will be enhanced at higher temperature. Therefore, $\beta$-SiC nanowires and rod-like $\beta$-SiC having larger diameters and shorter lengths are obtained at 1600 and $1700^{\circ} \mathrm{C}$, respectively.

\section{Conclusions}

A simple way to fabricate $1 \mathrm{D} \beta$-SiC nanostructures was developed in this study. $1 \mathrm{D} \beta-\mathrm{SiC} / \mathrm{SiO}_{2}$ nanochains, $\beta$-SiC nanowires and rod-like $\beta$-SiC were synthesized on graphite by pyrolysis of rice husks in argon atmosphere. The pyrolysis temperature and time greatly influence the morphology and microstructure of $\beta$-SiC. Finally, the 1D $\beta$-SiC nanostructures were suggested to grow by VS mechanism.

\section{References}

1) E. W. Wong, P. E. Sheehan and C. M. Lieber, Science, 277, 1971-1975 (1997).

2) Y. Cui and C. M. Lieber, Science, 291, 851-853 (2001).

3) W. M. Zhou, X. Liu and Y. F. Zhang, Appl. Phys. Lett., 89, 223124 (2006).

4) W. Yang, H. Araki, C. Tang, S. Thaveethavorn, A. Kohyama, H. Suzuki and T. Noda, Adv. Mater. (Deerfield Beach Fla.), 17, 1519-1523 (2005).

5) K. W. Wong, X. T. Zhou, F. C. K. Au, H. L. Lai, C. S. Lee and S. T. Lee, Appl. Phys. Lett., 75, 2918-2920 (1999).

6) S. C. Chiu and Y. Y. Li, J. Cryst. Growth, 311, 1036-1041 (2009).

7) J. J. Niu and J. N. Wang, Acta Mater., 57, 3084-3090 (2009).

8) G. Y. Li, X. D. Li, H. Wang and L. Liu, Solid State Sci., 11, 2167-2172 (2009).

9) J. Z. Guo, Y. Zuo, Z. J. Li, W. D. Gao and J. L. Zhang, Phys. E, 39, 262-266 (2007).

10) J. M. Nhut, R. Vieira, L. Pesant, J. P. Tessonnier, N. Keller, G. Ehret, C. P. Huu and M. J. Ledoux, Catal. Today, 76, 11-32 (2002).

11) X. M. Liu and K. F. Yao, Nanotechnology, 16, 2932-2935 (2005).

12) G. Attolini, F. Rossi, F. Fabbri, M. Bosi, B. E. Watts and G. Salviati, Mater. Lett., 63, 2581-2583 (2009). 
13) G. C. Xi, Y. K. Liu, X. Y. Liu, X. Q. Wang and Y. T. Qian, J. Phys. Chem. B, 110, 14172-14178 (2006).

14) Y. J. Hao, G. Q. Jin, X. D. Han and X. Y. Guo, Mater. Lett., 60, 1334-1337 (2006).

15) R. V. Krishnarao, M. M. Godkhindi, P. G. Mukunda and M. Chakraborty, J. Am. Ceram. Soc., 74, 2869-2875 (1991).

16) R. V. Krishnarao and Y. R. Mahajan, J. Eur. Ceram. Soc., 15, 1229-1234 (1995).

17) E. Mizuki, S. Okumura, H. Saito and S. Murao, Bioresour. Technol., 44, 47-51 (1993).

18) K. Koumoto, S. Takeda, C. H. Pai, T. Sato and H. Yanagida, J. Am. Ceram. Soc., 72, 1985-1987 (1989).

19) W. S. Seo and K. Koumoto, J. Am. Ceram. Soc., 79, 17771782 (1996).

20) Z. J. Li, W. D. Gao, A. Meng, Z. D. Geng and L. Gao, J. Phys.
Chem. C, 113, 91-96 (2009).

21) S. Nakashima and H. Harima, Phys. Status Solidi A, 162, 3963 (1997).

22) J. Fréchette and C. Carraro, J. Am. Chem. Soc., 128, 14774 14775 (2006).

23) Z. J. Li, J. L. Zhang, A. Meng and J. Z. Guo, J. Phys. Chem. B, 110, 22382-22386 (2006).

24) S. Nakashima, Y. Nakatake, H. Harima, M. Katsuno and N. Ohtani, Appl. Phys. Lett., 77, 3162-3164 (2000).

25) S. Zhu, D. Xi, Q. Li and R. Wang, J. Am. Ceram. Soc., 88, 2619-2621 (2005).

26) G. D. Wei, W. P. Qin, K. Z. Zheng, D. S. Zhang, J. B. Sun, J. J. Lin, R. J. Kim, G. F. Wang, P. F. Zhu and L. L. Wang, Cryst. Growth Des., 9, 1431-1435 (2009). 